\title{
Erratum to: Exploration of the Effectiveness and Acceptability of a Professional Mindfulness Retreat for Psychiatrists
}

\author{
Russell Razzaque $^{1} \cdot$ Lisa Wood $^{2}$
}

Published online: 7 September 2016

(C) Springer Science+Business Media New York 2016

Erratum to: Mindfulness (2016) 7:340-348

DOI 10.1007/s12671-015-0443-2

The incorrect p-value (0.049) was entered in Table 1 for the Working Alliance Inventory. The correct p-value is 0.053 . The error was made due to the original $p$-value being taken from the incorrect dataset (one which had not been screened for data inputting error). Therefore the authors would like to conclude that improvements in working alliance neared significance as a result of the mindfulness retreat. This indicates that working alliance may improve as a result of a mindfulness retreat but further research is required.

The online version of the original article can be found at http://dx.doi.org/ 10.1007/s12671-015-0443-2.

Russell Razzaque

russell.razzaque@nelft.nhs.uk

1 North East London Foundation Trust, Community Recovery Tam, Church Road, Romford RM3 0SH, UK

2 North East London Foundation Trust, Goodmayes Hospital, Barley Lane, Ilford IG3 8XJ, UK 